\title{
Papers
}

\section{Antenatal exposure to betamethasone: psychological functioning and health related quality of life 31 years after inclusion in randomised controlled trial}

Stuart R Dalziel, Vanessa K Lim, Anthony Lambert, Dianne McCarthy, Varsha Parag, Anthony Rodgers, Jane E Harding

\begin{abstract}
Objectives To determine if antenatal exposure to betamethasone for the prevention of neonatal respiratory distress syndrome alters psychological functioning and health related quality of life in adulthood.

Design Follow-up of the first and largest double blind, placebo controlled, randomised trial of a single course of antenatal betamethasone for the prevention of neonatal respiratory distress syndrome.

Setting Tertiary obstetric hospital in Auckland, New Zealand. Participants 192 adult offspring, mean age 31 years, of mothers who took part in a randomised controlled trial of antenatal betamethasone for the prevention of neonatal respiratory distress syndrome (87 exposed to betamethasone and 105 exposed to placebo).

Interventions Mothers received two doses of betamethasone or placebo 24 hours apart.

Main outcome measures Cognitive functioning assessed with Wechsler abbreviated scale of intelligence; working memory and attention assessed with Benton visual retention test, paced auditory serial addition test, and Brown attention deficit disorder scale; psychiatric morbidity assessed with Beck depression inventory II, state-trait anxiety inventory, and schizotypy traits questionnaire; handedness assessed with Edinburgh handedness inventory; health related quality of life assessed with short form 36 health survey.

Results No differences were found between groups exposed to betamethasone and placebo in cognitive functioning, working memory and attention, psychiatric morbidity, handedness, or health related quality of life.

Conclusions Prenatal exposure to a single course of betamethasone does not alter cognitive functioning, working memory and attention, psychiatric morbidity, handedness, or health related quality of life in adulthood. Obstetricians should continue to use a single course of antenatal betamethasone for the prevention of neonatal respiratory distress syndrome.
\end{abstract}

\section{Introduction}

A single course of antenatal glucocorticoids is recommended in the management of preterm labour for the prevention of neonatal respiratory distress syndrome. ${ }^{1}$ The use of glucocorticoids results in considerable reduction in mortality and morbidity, as well as costs, in infants born preterm. ${ }^{12}$ Follow-up studies of development into childhood suggest that no adverse effects occur through early childhood. ${ }^{3}$ However, information about long term psychological functioning and health related quality of life into adulthood after antenatal glucocorticoids remains scarce.

Other perinatal exposure to glucocorticoids has been associated with adverse neurodevelopmental outcomes. Repeated antenatal courses of glucocorticoids cause decreased fetal brain growth and myelination in sheep. ${ }^{4}$ Non-randomised studies in humans have reported decreased neonatal head circumference after repeated courses of antenatal glucocorticoids, ${ }^{5}$ with increased risk of hyperactivity in childhood. ${ }^{6}$ Furthermore, school age children exposed to postnatal glucocorticoids for neonatal chronic lung disease have lower IQ scores. ${ }^{7}$ To date the data on psychological functioning in adulthood after exposure to antenatal glucocorticoids are limited to one small follow-up study of a randomised controlled trial. No difference in cognitive functioning or self report of psychoneuroticism was found between groups in 81 participants aged 20. ${ }^{8}$ Conversely, a non-randomised cohort of 130 children at age 14 suggested better cognitive functioning in those exposed to glucocorticoids. ${ }^{9}$

Given the above concerns, we followed a cohort of neonatal survivors from the first and largest randomised controlled trial of antenatal glucocorticoids (the Auckland steroid trial, conducted by Liggins and Howie $^{10}$ ) to assess the long term effects on psychological functioning and health related quality of life in adulthood.

\section{Methods \\ Protocol}

Auckland steroid trial

The Auckland steroid trial and childhood follow-up have been described previously. ${ }^{3}{ }^{10}$ Briefly, between December 1969 and February 1974 all women expected to deliver between 24 and 36 weeks at the National Women's Hospital, Auckland, New Zealand, were eligible for enrolment unless immediate delivery was indicated. Women were randomised to an intramuscular injection of $6 \mathrm{mg}$ short acting betamethasone phosphate and 6 mg long acting betamethasone acetate or an identical looking placebo of $6 \mathrm{mg}$ cortisone acetate with a 70th of the glucocorticoid potency (trial 1). The allocated treatment was repeated 24 hours later if delivery had not occurred. If possible, labour was arrested with tocolytics for 48 hours. After the first 717 women had enrolled, the dose of betamethasone was doubled (trial 2). A total of 1142 women were enrolled and delivered 1218 babies. 
Primary endpoints were neonatal respiratory distress syndrome and perinatal death.

\section{Follow-up in adulthood}

Between February 2002 and December 2003 attempts were made to trace those "babies," now adults, who survived the neonatal period. Those located were invited to enter a follow-up study of adult cardiovascular and respiratory status, ${ }^{11}$ including collection of information about medical history and socioeconomic status. Between February 2003 and March 2004 we invited the subgroup of those who had participated in the cardiorespiratory follow-up who lived in the greater Auckland area to participate in the current study, which involved a structured assessment by a researcher in psychology (VKL). We obtained written informed consent from each participant.

\section{Outcome measures and definitions}

\section{Cognitive functioning}

We used the Wechsler abbreviated scale of intelligence to assess cognitive functioning. ${ }^{12}$ This comprises four subtests giving scales for full IQ, verbal IQ and performance IQ.

\section{Working memory and attention}

We used the Benton visual retention test ${ }^{13}$ the paced auditory serial addition test, ${ }^{14}$ and the Brown attention deficit disorder scale to assess working memory and attention. ${ }^{15}$ The Benton visual retention test assesses visual perception, visual memory, and visuoconstructive abilities by asking participants to copy from memory 10 increasingly difficult designs. Results are expressed as number of correct designs and a total error score.

The paced auditory serial addition test assesses sustained attention by asking participants to add 61 consecutive digits. As each digit is presented, the participant must sum that digit with the digit presented beforehand. The test is repeated with decreasing intervals between digits: 2.4 seconds, 2.0 seconds, 1.6 seconds, and 1.2 seconds. Results are expressed as a score of correct digits at each time interval. The Brown attention deficit disorder scale is a 40 item self completed questionnaire that measures symptoms of attention deficit disorder, with a total score out of 120 . We defined probable attention deficit disorder as a score of $>39$.

\section{Psychiatric morbidity}

We used the Beck depression inventory $I I,{ }^{16}$ the trait portion of the state-trait anxiety inventory, ${ }^{17}$ and the schizotypy traits questionnaire to assess psychiatric morbidity. ${ }^{18}$ The Beck depression inventory II is a 21 item self completed questionnaire that measures presence and severity of depression symptoms as listed in the Diagnostic and Statistical Manual of Mental Disorders, fourth edition. We defined probable depression as a score of $>13$. The trait portion of the state-trait anxiety inventory is a 20 item self completed questionnaire that measures individual differences in proneness to anxiety. We defined probable anxiety as a score above the 80 th centile. The schizotypy traits questionnaire is a 37 item self completed questionnaire that measures the minor manifestations of a psychotic disorder. Results are expressed as a total score and three subscales-magical ideation, unusual perceptual experiences, and paranoid ideation and suspiciousness.

\section{Handedness}

We used the Edinburgh handedness inventory to assess handedness. ${ }^{19}$ This is a 10 item self completed questionnaire that measures hand preference for 10 everyday activities. Results are expressed as a laterality quotient, where right handedness is +30 to +100 , ambidextrous is -30 to +30 , and left handedness is -100 to -30 .

\section{Health related quality of life}

We assessed health related quality of life by using the Australasian version of the short form 36 health survey (SF-36), which has been validated in 7862 New Zealanders. ${ }^{20}$ This is a 36 item self completed questionnaire that measures eight multi-item domains of perceived health related quality of life. Scores range from 0 (worst) to 100 (best) for all domains. Five domains (physical functioning, role limitation due to physical problems, bodily pain, social functioning, role limitation due to emotional problems) define health status by absence of disability, and the maximum score is achieved when no disability is reported. Three domains (general health perception, vitality, and mental health) define both positive and negative health status, and a score of 50 indicates neither positive nor negative status. We also asked participants questions to determine the presence of visual, hearing, and speech abnormalities.

\section{Assignment}

The chief pharmacist used random number tables to generate randomisation and held the randomisation key. The study drug was supplied in identical numbered ampoules.

\section{Masking}

Staff who enrolled mothers and who cared for and assessed participants in the neonatal period were blind to study group allocation. Adult participants and all members of the study team involved in tracing, recruitment, assessment and analysis were also unaware of the participants' in utero exposure.

\section{Participant flow and follow-up}

Of the 988 neonatal survivors from the Auckland steroid trial, $713(72 \%)$ were successfully traced at 30 years. Of these, 534 completed the cardiorespiratory follow-up- $-56 \%$ of those presumed to be alive and $80 \%$ of those traced and known to be alive. ${ }^{11}$ Of these, 280 were eligible for the current study (that is, lived in the greater Auckland area), of whom 192 (69\%) participated (figure).

\section{Analyses}

We used SAS version 8.02 (SAS Institute, Cary, NC) to analyse data on an intention to treat basis. We compared continuous variables with unpaired $t$ tests or Mann-Whitney tests and categorical data with $\chi^{2}$ tests as appropriate. We log transformed variables with skewed distributions. If the distribution remained skewed, we present data as medians. Primary analyses were unadjusted. Secondary analyses used multiple linear regression to adjust for confounding by sex, birth weight, gestational age, and socioeconomic status decided a priori. We explored further confounders by using the change in estimates technique at the $10 \%$ level. ${ }^{21}$ We created birth weight standard deviation (z) scores by using data from all New Zealand deliveries in 1990-1. We assigned New Zealand socioeconomic index scores from occupational data. ${ }^{11}$

\section{Results}

\section{Recruitment}

Eighty seven participants exposed to betamethasone and 105 participants exposed to placebo took part (66\% v 71\% of those eligible; $\mathrm{P}=0.36)$. Mean (SD) age at follow-up was $31.2(1.1)$ and 31.1 (1.1) years in the two groups. 


\section{Background characteristics}

Those who participated in this study were more likely to have had respiratory distress syndrome but had otherwise similar perinatal characteristics to the entire cohort of non-participants presumed to be alive at age 30 (table 1). Those who participated were less likely to have been from a multiple pregnancy, to have obtained fewer than four years of high school education, or to be in the lowest socioeconomic group but had otherwise similar perinatal and adult characteristics to those who were eligible for this study (lived in the Auckland area) but declined participation (table 1). No significant differences in perinatal or adult characteristics existed between the betamethasone and placebo exposed participants who took part (table 2).

\section{Previous psychiatric diagnosis}

A previous psychiatric diagnosis was reported by six (7\%) betamethasone exposed and six (6\%) placebo exposed participants (relative risk $1.2,95 \%$ confidence interval 0.40 to $3.6 ; \mathrm{P}=0.74$ ). One placebo exposed participant had schizophrenia. The other diagnoses were affective and anxiety conditions.

\section{Psychological functioning}

No difference existed between groups in measures of cognitive functioning, working memory and attention, depression, anxiety, schizotypy, or handedness (table 3). Adjustment for previous psychiatric diagnosis did not change the depression, anxiety, or schizotypy results.

\section{Health related quality of life}

We found no difference between groups in the eight domains of the SF-36 (table 3). No difference existed between groups in the numbers reporting visual or hearing difficulties. However, betamethasone exposed participants reported significantly fewer speech difficulties. All participants with speech difficulties reported a mild impairment, in that they were partially understood when speaking to strangers but completely understood when speaking to those who knew them well.
Multivariate analysis

Adjustment for sex, birth weight, gestational age, and socioeconomic status did not change the results.

\section{Discussion}

We studied 192 neonatal survivors at 31 years of age from the first and largest randomised controlled trial of antenatal betamethasone for the prevention of neonatal respiratory distress syndrome. We found that antenatal exposure to betamethasone did not alter cognitive functioning, working memory and attention, psychiatric morbidity, handedness, or health related quality of life at age 31 .

The only other report of outcome in adulthood after a randomised controlled trial of antenatal glucocorticoids involved 81 participants at a mean age of 20 and found no differences in cognitive functioning, handedness, or psychopathology. ${ }^{8}$ Our study is the first to report health related quality of life into adulthood after exposure to antenatal glucocorticoids.

\section{Comparison with other studies}

Our findings are consistent with previous childhood follow-up studies from both the Auckland steroid trial and other randomised trials of antenatal glucocorticoids. ${ }^{32}$ MacArthur et al followed 258 children at age 4 and 250 children at age 6 from the first 318 neonatal survivors of the Auckland steroid trial (trial 1). ${ }^{3}$ They reported no overall differences in cognition between the two groups. However, betamethasone exposed children had lower scores on the Raven's progressive matrices test (a test of non-verbal reasoning) and two of the visual subsets of the Illinois test of psycholinguistic abilities at age 6 . These differences were thought to be unimportant, and this is consistent with our findings of no difference between groups in the Benton visual retention test and the matrix subtest of the Wechsler abbreviated scale of intelligence (a test of non-verbal reasoning). The authors of the second largest randomised trial of antenatal glucocorticoids

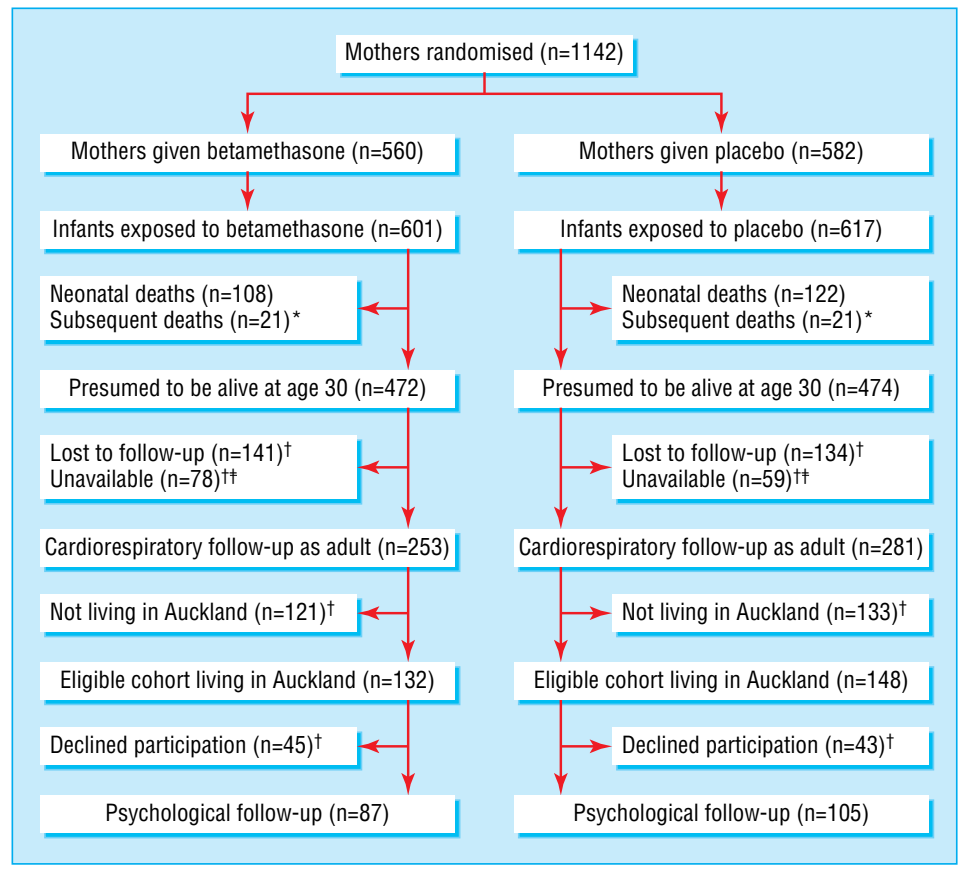

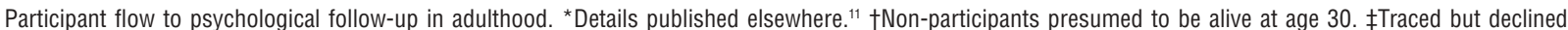
participation in cardiorespiratory adult follow-up or residing overseas and not returning to New Zealand within timeframe of study 
Table 1 Characteristics of infants who participated in this study compared with those who were eligible but declined participation and with all non-participants presumed to be alive at age 30 . Values are numbers (percentages) unless stated otherwise

\begin{tabular}{|c|c|c|c|c|c|}
\hline \multirow[b]{2}{*}{ Characteristic } & \multirow[b]{2}{*}{ Participants $(n=192)$} & \multicolumn{2}{|c|}{$\begin{array}{l}\text { Eligible for participation but declined } \\
\qquad(\mathrm{n}=88)\end{array}$} & \multicolumn{2}{|c|}{$\begin{array}{l}\text { Non-participants presumed to be alive at age } 30 \\
\qquad(\mathrm{n}=754)\end{array}$} \\
\hline & & Values & P value & Values & P value \\
\hline \multicolumn{6}{|l|}{ Maternal characteristics } \\
\hline Multiple pregnancy & $22(11)$ & $19(22)$ & 0.03 & $91(12)$ & 0.82 \\
\hline Unplanned premature labour & $159(83)$ & $68(77)$ & 0.27 & $625(83)$ & 0.98 \\
\hline Hypertension & $16(8.3)$ & $8(9.1)$ & 0.83 & $51(6.8)$ & 0.45 \\
\hline Gestational diabetes & $3(1.6)$ & $3(3.4)$ & 0.38 & $10(1.3)$ & 0.73 \\
\hline Haemolytic disease & $8(4.2)$ & $5(5.7)$ & 0.58 & $33(4.4)$ & 0.90 \\
\hline Median (IQR) gestational age at entry (days) & $231(216-242)$ & $235(213-244)$ & 0.63 & $232(217-244)$ & 0.52 \\
\hline Median (IQR) entry/delivery interval (days) & $4.8(1.7-36)$ & $3.3(1.4-29)$ & 0.20 & $4.4(1.8-38)$ & 0.95 \\
\hline Trial 1 & $120(63)$ & $49(56)$ & 0.28 & $465(62)$ & 0.83 \\
\hline Betamethasone treatment & $87(45)$ & $45(51)$ & 0.36 & $385(51)$ & 0.16 \\
\hline \multicolumn{6}{|l|}{ Neonatal characteristics } \\
\hline Male sex & $99(52)$ & $44(50)$ & 0.81 & $424(56)$ & 0.25 \\
\hline Median (IQR) gestational age at delivery (days) & $245(234-266)$ & $245(231-259)$ & 0.20 & 248 (236-266) & 0.44 \\
\hline Term delivery & $66(34)$ & $23(26)$ & 0.17 & $268(36)$ & 0.76 \\
\hline Mean (SD) birth weight $(\mathrm{g})$ & $2403(796)$ & $2243(801)$ & 0.12 & $2416(722)$ & 0.83 \\
\hline Mean (SD) birth weight $z$ score & $-0.32(0.98)$ & $-0.39(1.16)$ & 0.58 & $-0.40(0.97)$ & 0.33 \\
\hline Birth weight $<10$ th centile & $27(14)$ & $18(20)$ & 0.18 & $127(17)$ & 0.35 \\
\hline Fetal distress & $27(14)$ & $12(14)$ & 0.92 & $105(14)$ & 0.96 \\
\hline 5 min Apgar >7 & $148(77)$ & $69(78)$ & 0.81 & $599(79)$ & 0.47 \\
\hline RDS & $21(11)$ & $9(10)$ & 0.86 & $48(6.4)$ & 0.03 \\
\hline RDS (moderate or severe) & $17(8.9)$ & $6(6.8)$ & 0.56 & $32(4.2)$ & 0.01 \\
\hline \multicolumn{6}{|l|}{ Adult characteristics } \\
\hline \multicolumn{6}{|l|}{ Ethnicity: } \\
\hline European & $144(75)$ & $62(70)$ & \multirow[t]{4}{*}{0.34} & & \\
\hline Maori & $35(18)$ & $23(26)$ & & & \\
\hline Pacific & $12(6.3)$ & $3(3.4)$ & & & \\
\hline Other & $1(0.5)$ & $0(0)$ & & & \\
\hline \multicolumn{6}{|l|}{ Tobacco use: } \\
\hline Non-smoker & $102(53)$ & $42(48)$ & \multirow[t]{3}{*}{0.12} & & \\
\hline Former smoker & $38(20)$ & $12(14)$ & & & \\
\hline Current smoker & $52(27)$ & $34(39)$ & & & \\
\hline \multicolumn{6}{|l|}{ Alcohol useł: } \\
\hline Non-drinker & $46(24)$ & $24(27)$ & \multirow[t]{3}{*}{0.82} & & \\
\hline Social drinker & $118(61)$ & $51(58)$ & & & \\
\hline Heavy drinker & $28(15)$ & $13(15)$ & & & \\
\hline \multicolumn{6}{|l|}{ Marital status: } \\
\hline Single & $62(32)$ & $33(38)$ & \multirow[t]{3}{*}{0.20} & & \\
\hline Separated/divorced/widowed & $6(3.1)$ & $6(6.8)$ & & & \\
\hline Married or living with partner & $124(65)$ & $49(56)$ & & & \\
\hline \multicolumn{6}{|l|}{ Education level: } \\
\hline High school $<4$ years & $35(18)$ & $35(40)$ & \multirow[t]{4}{*}{$<0.001$} & & \\
\hline High school $\geq 4$ years & $48(25)$ & $19(22)$ & & & \\
\hline Polytechnic & $62(32)$ & $23(26)$ & & & \\
\hline University & $47(24)$ & $11(13)$ & & & \\
\hline \multicolumn{6}{|l|}{ Socioeconomic status§: } \\
\hline 1 & $9(4.7)$ & $4(4.7)$ & \multirow[t]{6}{*}{0.05} & & \\
\hline 2 & $34(18)$ & $14(16)$ & & & \\
\hline 3 & 61 (32) & $13(15)$ & & & \\
\hline 4 & $45(24)$ & $30(35)$ & & & \\
\hline 5 & $28(15)$ & $14(16)$ & & & \\
\hline 6 & $14(7.3)$ & $11(13)$ & & & \\
\hline
\end{tabular}

IQR=interquartile range; RDS=respiratory distress syndrome.

*Includes infants eligible for participation but who declined (see figure).

†For differences compared with participants.

łBased on standard units of alcohol consumption, adjusted for sex. ${ }^{11}$

§Based on occupation: 1=highest socioeconomic group. ${ }^{11}$ Occupation could not be coded for one participant and two people who were eligible for participation but declined.

followed 339 infants at 36 months of age and reported no difference in cognitive outcome. ${ }^{22}$

Post hoc calculations indicate that our study had $80 \%$ power $(\alpha=0.05)$ to detect a difference between treatment groups of $5 \%$ for IQ, 7\% for Brown attention deficit disorder scale total scores, $3 \%$ for state-trait anxiety inventory scores, and 10\% for SF-36 mental health scores. Thus clinicians can be confident that the relatively small fetal glucocorticoid exposure resulting from a single course of antenatal betamethasone for the prevention of neonatal respiratory distress syndrome has no clinically detectable effect on cognitive functioning, working memory and attention, or psychiatric morbidity into adulthood. This 
Table 2 Characteristics of participants exposed to betamethasone and placebo. Values are numbers (percentages) unless stated otherwise

\begin{tabular}{|c|c|c|c|}
\hline Characteristic & $\begin{array}{l}\text { Betamethasone } \\
\quad(\mathrm{n}=87)\end{array}$ & Placebo (n=105) & $P$ value \\
\hline \multicolumn{4}{|l|}{ Maternal characteristics } \\
\hline Multiple pregnancy & $12(14)$ & $10(10)$ & 0.36 \\
\hline Unplanned premature labour & $71(82)$ & $88(84)$ & 0.69 \\
\hline Hypertension & $10(11)$ & $6(5.7)$ & 0.15 \\
\hline Gestational diabetes & $1(1.2)$ & $2(1.9)$ & 1.00 \\
\hline Haemolytic disease & $3(3.4)$ & $5(4.8)$ & 0.73 \\
\hline $\begin{array}{l}\text { Median (IQR) gestational age at entry } \\
\text { (days) }\end{array}$ & $231(212-240)$ & $232(217-242)$ & 0.50 \\
\hline $\begin{array}{l}\text { Median (IQR) entry/delivery interval } \\
\text { (days) }\end{array}$ & $4.6(1.9-39)$ & $5.6(1.6-36)$ & 0.56 \\
\hline Trial 1 & $55(63)$ & $65(62)$ & 0.85 \\
\hline \multicolumn{4}{|l|}{ Neonatal characteristics } \\
\hline Male sex & $46(53)$ & $53(50)$ & 0.74 \\
\hline $\begin{array}{l}\text { Median (IQR) gestational age at } \\
\text { delivery (days) }\end{array}$ & $245(235-266)$ & $248(232-266)$ & 0.83 \\
\hline Term delivery & $27(31)$ & $39(37)$ & 0.38 \\
\hline Mean (SD) birth weight (g) & $2369(817)$ & $2432(782)$ & 0.59 \\
\hline Mean (SD) birth weight $z$ score & $-0.40(0.93)$ & $-0.25(1.01)$ & 0.31 \\
\hline Birth weight $<10$ th centile & $15(17)$ & $12(11)$ & 0.25 \\
\hline Fetal distress & $9(10)$ & $18(17)$ & 0.18 \\
\hline 5 min Apgar $>7$ & $70(80)$ & $78(74)$ & 0.31 \\
\hline RDS & $8(9.2)$ & $13(12)$ & 0.48 \\
\hline RDS (moderate or severe) & $7(8.0)$ & $10(9.5)$ & 0.72 \\
\hline \multicolumn{4}{|l|}{ Adult characteristics } \\
\hline \multicolumn{4}{|l|}{ Ethnicity: } \\
\hline European & $67(77)$ & $77(73)$ & \multirow[t]{4}{*}{0.70} \\
\hline Maori & $14(16)$ & $21(20)$ & \\
\hline Pacific & $6(6.9)$ & $6(5.7)$ & \\
\hline $\begin{array}{l}\text { Other } \\
\end{array}$ & 0 & $1(1.0)$ & \\
\hline \multicolumn{4}{|l|}{ Tobacco use: } \\
\hline Non-smoker & $46(53)$ & $56(53)$ & \multirow[t]{3}{*}{0.61} \\
\hline Former smoker & $15(17)$ & $23(22)$ & \\
\hline Current smoker & $26(30)$ & $26(25)$ & \\
\hline \multicolumn{4}{|l|}{ Alcohol use*: } \\
\hline Non-drinker & $24(28)$ & $22(21)$ & \multirow[t]{3}{*}{0.52} \\
\hline Social drinker & $50(57)$ & $68(65)$ & \\
\hline Heavy drinker & $13(15)$ & $15(14)$ & \\
\hline \multicolumn{4}{|l|}{ Marital status: } \\
\hline Single & $28(32)$ & $34(32)$ & \multirow[t]{3}{*}{0.97} \\
\hline Separated/divorced/widowed & $3(3.4)$ & $3(2.9)$ & \\
\hline Married or living with partner & $56(64)$ & $68(65)$ & \\
\hline \multicolumn{4}{|l|}{ Education level: } \\
\hline High school $<4$ years & $19(22)$ & $16(15)$ & \multirow[t]{4}{*}{0.52} \\
\hline High school $\geq 4$ years & $22(25)$ & $26(25)$ & \\
\hline Polytechnic & $24(28)$ & $38(36)$ & \\
\hline University & $22(25)$ & $25(24)$ & \\
\hline \multicolumn{4}{|l|}{ Socioeconomic statust: } \\
\hline 1 & $3(3.4)$ & $6(5.8)$ & \multirow[t]{6}{*}{0.62} \\
\hline 2 & $17(20)$ & $17(16)$ & \\
\hline 3 & $23(26)$ & $38(37)$ & \\
\hline 4 & $22(25)$ & $23(22)$ & \\
\hline 5 & 14 (16) & 14 (13) & \\
\hline 6 & $8(9.2)$ & $6(5.8)$ & \\
\hline
\end{tabular}

IQR=interquartile range; $R D S=$ =respiratory distress syndrome.

*Based on standard units of alcohol consumption, adjusted for sex."

†Based on occupation: 1=highest socioeconomic group. ${ }^{11}$

confidence cannot be extrapolated to other situations of much larger glucocorticoid exposures in the perinatal period. Animal studies and non-randomised evidence suggest possible adverse psychological sequelae after repeated courses of antenatal glucocorticoids. ${ }^{45}$ Long term follow-up of recent randomised controlled trials is essential to clarify the clinical relevance of these effects. Follow-up of 146 school age children from a randomised controlled trial of much larger doses of glucocorticoids for treatment of neonatal chronic lung disease also found poorer cognitive functioning in those exposed to glucocorticoids. $^{\text {? }}$

We found that participants exposed to betamethasone reported a lower incidence of speech difficulties than those exposed to placebo. The self reported speech impairment described was clinically mild, but the difference between groups cannot be explained by cerebral palsy, cognitive functioning, or ethnicity. MacArthur et al reported no difference between groups in incidence of stammering, stutter, or intelligibility of speech at 4 and 6 years of age. ${ }^{3}$ The differences between groups in adulthood must be interpreted with caution in light of the multiple comparisons done in the analysis and hence the possibility of a type I error.

\section{Limitations}

Our study has several limitations. Only $69 \%$ of the eligible cohort of neonatal survivors living in the Auckland region participated in this study. Although this obviously introduces the potential for selection bias, the likely direction of such bias remains uncertain. ${ }^{23}{ }^{24}$ However, lack of complete follow-up would bias our results only if the association between exposure to betamethasone and psychological and health related quality of life outcomes differed between those who did and those who did not participate. As the original trial was randomised, we have no reason to think that this might be the case. Furthermore, the Auckland steroid trial is particularly suited to long term follow-up, as very few mothers were not considered for randomisation and similar numbers of neonatal survivors with similar perinatal morbidity were available from both treatment groups.

Further potential for selection bias is introduced by the geographical restriction of study participants to those living in the Auckland region, for logistic and funding reasons. However, once again, this would bias our results only if the association between betamethasone exposure and psychological and health related quality of life outcomes differed between those living in Auckland and those living elsewhere. This seems unlikely given the randomised nature of the original trial, the similar proportion of the survivors from each treatment group who were eligible for the study, and the similar proportion who took part from among those eligible. Furthermore, the only difference in perinatal variables between the participants and the total cohort of neonatal survivors presumed to be alive at age 30 was the higher incidence of neonatal respiratory distress syndrome in participants.

\section{Implications}

The applicability of our findings to current clinical practice is less clear cut. Our study only included nine infants born $<30$ weeks' gestation. However, the expected neonatal outcome for these very premature infants today is similar to that of our more mature cohort 30 years ago. Furthermore, most preterm babies are born after 30 weeks' gestation, and this group is most similar to the cohort reported in this study. Nevertheless, further follow-up studies of more recent randomised trial cohorts will be helpful in clarifying any possible long term effects of exposure to antenatal betamethasone at much earlier gestations than was the case in this study.

\section{Conclusions}

We conclude that antenatal exposure to a single course of betamethasone does not alter cognitive functioning, working memory and attention, psychiatric morbidity, handedness, or health related quality of life in adulthood. Obstetricians should 
Table 3 Psychological functioning and health related quality of life outcomes in groups exposed to betamethasone and placebo

\begin{tabular}{|c|c|c|c|c|c|}
\hline \multirow[b]{2}{*}{ Outcome } & \multicolumn{3}{|c|}{ Measured outcome } & \multirow[b]{2}{*}{ Difference $(95 \% \mathrm{CI})$} & \multirow[b]{2}{*}{$P$ value } \\
\hline & Measurement & Betamethasone $(\mathrm{n}=87)$ & Placebo $(n=105)$ & & \\
\hline \multicolumn{6}{|l|}{ Cognitive functioning } \\
\hline Full IQ & Mean (SD) & $102.6(12.5)$ & $103.7(13.5)$ & $-1.0(-4.8$ to 2.7$)$ & 0.58 \\
\hline Verbal IQ & Mean (SD) & $97.6(11.9)$ & $98.3(12.8)$ & $-0.8(-4.3$ to 2.8$)$ & 0.67 \\
\hline Performance IQ & Mean (SD) & $107.2(13.8)$ & $108.3(14.7)$ & $-1.1(-5.2$ to 3.0$)$ & 0.59 \\
\hline \multicolumn{6}{|l|}{ Working memory and attention } \\
\hline Benton: total correct score & Mean (SD) & $7.0(1.7)$ & $7.2(1.8)$ & $-0.1(-0.6$ to 0.4$)$ & 0.59 \\
\hline Benton: total number of errors & Mean (SD) & $3.8(2.6)$ & $3.7(3.0)$ & $-0.1(-0.7$ to 0.9$)$ & 0.89 \\
\hline \multicolumn{6}{|c|}{ Paced auditory serial addition test, correct score at: } \\
\hline 2.4 second & Median (IQR) & 41 (27-49) & $43(28-49)$ & $-1 \quad(-5$ to 3$)$ & 0.72 \\
\hline 2.0 second & Median (IQR) & $37(27-46)$ & $37(26-45)$ & $0(-2$ to 5$)$ & 0.59 \\
\hline 1.6 second & Median (IQR) & $29(22-40)$ & $30(20-39)$ & $0(-3$ to 4$)$ & 0.77 \\
\hline 1.2 second & Median (IQR) & $24(14-34)$ & $26(15-33)$ & 0 (-4 to 2$)$ & 0.60 \\
\hline Brown ADD scale: total score & Log mean & 25.6 & 26.9 & $1(0.8 \text { to } 1.1)^{\star}$ & 0.58 \\
\hline Probable ADD & No $(\%)$ & $16(18)$ & $30(29)$ & $0.64(0.38$ to 1.1$) \dagger$ & 0.10 \\
\hline \multicolumn{6}{|l|}{ Psychiatric morbidity } \\
\hline BDI-II total score & Median (IQR) & $5(2-12)$ & $5(1-10)$ & $1(-1$ to 2$)$ & 0.44 \\
\hline Probable depression & No $(\%)$ & $16(18)$ & $17(16)$ & $1.1(0.61$ to 2.1$) \dagger$ & 0.69 \\
\hline State-trait anxiety inventory: total & Log mean & 34.1 & 34.5 & $1(0.9 \text { to } 1.1)^{*}$ & 0.74 \\
\hline Probable anxiety & No $(\%)$ & $17(20)$ & $27(26)$ & $0.76(0.44$ to 1.3$) \dagger$ & 0.31 \\
\hline \multicolumn{6}{|l|}{ Schizotypy traits questionnaire: } \\
\hline Total & Median (IQR) & $11(6-15)$ & $10(7-15)$ & $0(-2$ to 2$)$ & 0.78 \\
\hline Magical ideation & Median (IQR) & $3(1-4)$ & $3(1-4)$ & $0(-1$ to 1$)$ & 0.93 \\
\hline Unusual perceptual experiences & Median (IQR) & $1(0-3)$ & $2(0-3)$ & $0(0$ to 0$)$ & 0.97 \\
\hline Paranoid ideation and suspiciousness & Median (IQR) & $1(0-3)$ & $1(0-3)$ & $1(-1$ to 2$)$ & 0.70 \\
\hline \multicolumn{6}{|l|}{ Handedness } \\
\hline Laterality quotient & Median (IQR) & $90(71-100)$ & $86(60-100)$ & $0(0$ to 8$)$ & 0.22 \\
\hline \multicolumn{6}{|l|}{ Health related quality of life } \\
\hline \multicolumn{6}{|l|}{ SF-36: } \\
\hline Physical functioning & Mean (SD) & $86(24)$ & $89(17)$ & $-3(-9$ to 2$)$ & 0.27 \\
\hline Role limitation due to physical problems & Mean (SD) & $78(37)$ & $79(37)$ & $-1 \quad(-12$ to 9$)$ & 0.82 \\
\hline Bodily pain & Mean (SD) & $72(25)$ & $76(21)$ & -4 (-11 to 2$)$ & 0.19 \\
\hline General health perception & Mean (SD) & $74(21)$ & $75(21)$ & $-2(-7$ to 4$)$ & 0.61 \\
\hline Vitality & Mean (SD) & $59(19)$ & $62(19)$ & $-3(-8$ to 2$)$ & 0.28 \\
\hline Social functioning & Mean (SD) & $79(25)$ & $83(23)$ & $-3(-10$ to 3$)$ & 0.32 \\
\hline Role limitation due to emotional problems & Mean (SD) & $72(41)$ & $77(38)$ & $-5(-16$ to 6$)$ & 0.37 \\
\hline Mental health & Mean (SD) & $72(18)$ & $75(17)$ & $-3(-8$ to 2$)$ & 0.23 \\
\hline Participants reporting visual difficulty & No $(\%)$ & $18(21)$ & $24(23)$ & 0.91 (0.53 to 1.6$) \dagger$ & 0.72 \\
\hline Participants reporting hearing difficulties & No $(\%)$ & $1(1.2)$ & $5(4.8)$ & $0.24(0.03$ to 2.0$) \dagger$ & 0.22 \\
\hline Participants reporting speech difficulties & No $(\%)$ & $1(1.2)$ & $9(8.6)$ & $0.13(0.01$ to 1.0$) \dagger$ & 0.02 \\
\hline
\end{tabular}

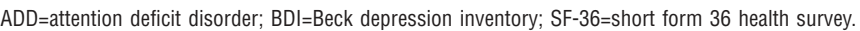

${ }^{\star}$ A difference between log means is a ratio and is non-significant if $95 \%$ confidence interval includes 1 .

†Relative risk ( $95 \%$ confidence interval).

continue to use a single course of antenatal glucocorticoids for the prevention of neonatal respiratory distress syndrome.

We are indebted to the mothers and their children for participation in the original Auckland steroid trial and the subsequent follow-up studies. We thank Ross Howie and Mont Liggins for making the Auckland steroid trial data available. We also thank Mary Wills, Maria Harrison, and Sue Hawkins for help with study recruitment; John Thompson for making data available to create birth weight z scores; and Natalie Walker, Colin Mantell, and Harry Rea for their involvement in the cardiorespiratory follow-up.

Contributors: SRD, AL, DMcC, AR, and JEH conceived the study. VKL collected the data. SRD, VP, and JEH did the statistical analysis. SRD, VKL, AL, DMcC, VP, AR, and JEH wrote the manuscript. SRD and JEH are guarantors.

Funding: Auckland Medical Research Foundation, Health Research Council of New Zealand, and New Zealand Lottery Grants Board. The study sponsors had no role in study design, data collection, data analysis, data interpretation, the writing of the paper, or in the decision to submit the paper for publication.

Competing interests: None declared.

Ethical approval: The Auckland Regional Ethics Committee approved this follow-up study.

\section{What is already known on this topic}

A single course of antenatal glucocorticoids reduces neonatal mortality and morbidity after preterm birth and is widely used for the prevention of neonatal respiratory distress syndrome

No studies have adequately looked at psychological functioning and health related quality of life in adulthood after antenatal exposure to glucocorticoids

\section{What this study adds}

Antenatal exposure to betamethasone did not alter psychological functioning or health related quality of life at 31 years of age

Obstetricians should continue to use a single course of antenatal glucocorticoids for the prevention of neonatal respiratory distress syndrome 
1 National Institutes of Health. Effect of corticosteroids for fetal maturation on perinatal outcomes. NIH Consensus Statement 1994;12(2):1-24.

2 Crowley P. Prophylactic corticosteroids for preterm birth. Cochrane Database Syst Re 2000;(2):CD000065

3 MacArthur BA, Howie RN, Dezoete JA, Elkins J. School progress and cognitive development of 6-year-old children whose mothers were treated antenatally with betamethasone. Pediatrics 1982;70:99-105.

4 Huang WL, Harper CG, Evans SF, Newnham JP, Dunlop SA. Repeated prenatal corticosteroid administration delays myelination of the corpus callosum in fetal sheep. Int $J$ Deo Neurosci 2001;19:415-25

5 French NP, Hagan R, Evans SF, Godfrey M, Newnham JP. Repeated antenatal corticosteroids: size at birth and subsequent development. Am J Obstet Gynecol 1999;180:114-21.

6 French NP, Hagan R, Evans SF, Mullan A, Newnham JP. Repeated antenatal corticosteroids: effects on cerebral palsy and childhood behavior. Am J Obstet Gynecol 2004;190:588-95.

7 Yeh TF, Lin YJ, Lin HC, Huang CC, Hsieh WS, Lin CH, et al. Outcomes at school age after postnatal dexamethasone therapy for lung disease of prematurity. $N$ Engl J Med 2004:350:1304-13.

8 Dessens AB, Haas HS, Koppe JG. Twenty-year follow-up of antenatal corticosteroid treatment. Pediatrics 2000;105:E77.

9 Doyle LW, Ford GW, Rickards AL, Kelly EA, Davis NM, Callanan C, et al. Antenatal corticosteroids and outcome at 14 years of age in children with birth weight less than 1501 grams. Pediatrics 2000;106:E2.

10 Liggins GC, Howie RN. A controlled trial of antepartum glucocorticoid treatment for prevention of the respiratory distress syndrome in premature infants. Pediatrics 1972;50:515-25.

11 Dalziel SR, Walker NK, Parag V, Mantell CH, Rea HH, Rodgers A, et al. Cardiovascular risk factors after exposure to antenatal betamethasone: 30-year follow-up of a randomised controlled trial Lancet 2005;365:1856-69.

12 Wechsler D. Wechsler abbreviated scale of intelligence. San Antonio, TX: Psychological Corporation, 1999

13 Sivan AB. Benton visual retention test. 5th ed. San Antonio, TX: Psychological Corporation, 1992.

14 Gronwall DM. Paced auditory serial-addition task: a measure of recovery from concussion. Percept Mot Skills 1977;44:367-73.

15 Brown TE. Brown attention deficit disorder scales. San Antonio, TX: Psychological Corporation, 1996.
16 Beck AT. Beck depression inventory-II (BDI-II). San Antonio, TX: Psychological Corporation, 1996.

17 Spielberger CD. State-trait anxiety inventory (form Y). Redwood City, CA: Mind Garden, 1983.

18 Claridge G, Broks P. Schizotypy and hemisphere function: I. Theoretical considerations and the measurement of schizotypy. Pers Indiv Dif 1984;5:633-48.

19 Oldfield RC. The assessment and analysis of handedness: the Edinburgh inventory. Neuropsychologia 1971;9:97-113.

20 Scott KM, Tobias MI, Sarfati D, Haslett SJ. SF-36 health survey reliability, validity and norms for New Zealand. Aust N Z J Public Health 1999;23:401-6.

21 Greenland S. Modeling and variable selection in epidemiologic analysis. Am J Public Health 1989:79:340-9.

22 Collaborative Group on Antenatal Steroid Therapy Effects of antenatal dexamethasone administration in the infant: long-term follow-up. J Pediatr 1984;104:259-67.

23 Castro L, Yolton K, Haberman B, Roberto N, Hansen NI, Ambalavanan N, et al. Bias in reported neurodevelopmental outcomes among extremely low birth weight survivors. Pediarics 2004;114:404-10.

24 Tin W, Fritz S, Wariyar U, Hey E. Outcome of very preterm birth: children reviewed with ease at 2 years differ from those followed up with difficulty. Arch Dis Child Fetal Neonatal Ed 1998;79:F83-7.

(Accepted 10 August 2005)

doi 10.1136/bmj.38576.494363.E0

Clinical Trials Research Unit, University of Auckland, Private Bag 92019,

Auckland, New Zealand

Stuart R Dalziel research fellow

Varsha Parag biostatistician

Anthony Rodgers director

Department of Psychology, University of Auckland

Vanessa K Lim research fellow

Anthony Lambert senior lecturer

Dianne McCarthy professor

Liggins Institute, University of Auckland

Jane E Harding professor

Correspondence to:J E Harding j.harding@auckland.ac.nz 